\title{
The European Journal of Ageing develops successfully: impressions at the start of volume 6
}

\author{
Hans-Werner Wahl · Dorly J. H. Deeg
}

Published online: 26 February 2009

(C) Springer-Verlag 2009

This issue marks the start of the sixth volume of the European Journal of Ageing (EJA): Social, Behavioural and Health Perspectives. Five volumes have been launched, showing that the journal has proven its sustainability. Now, the consolidation of the journal's platform has begun. This is primarily the success of those having contributed to the journal as authors, but also as consulting editors, editorial board members and external reviewers (see also acknowledgement at the end of this issue). In addition, Springer has taken strong action to bring the journal to the public as well as to the international scientific community, in particular via successful applications for coverage of our journal by Thompson Scientific, and via their presence with a Springer booth at key conferences such as the European Population Conference in Barcelona, July 2008, and the Annual Scientific Meeting of the Gerontological Society of America in November 2008.

Beginning in 2009, the impact factor production by Thompson Scientific will be implemented, and this of course means a very major step in the journal's development. The impact factor for 2008 is calculated as the number of citations in scientific journals in 2008 of EJA articles published in 2006 and 2007, divided by the number of EJA articles published in 2008. Our own calculation brings the journal's impact factor in 2008 exactly to 1.00 .

\section{H.-W. Wahl ( $\bowtie)$}

Department of Psychological Ageing Research, Institute of Psychology, University of Heidelberg, Bergheimer Straße 20, 69115 Heidelberg, Germany

e-mail: eja@psychologie.uni-heidelberg.de

\section{J. H. Deeg}

VU University Medical Center, Van der Boechorstraat 7, 1081 BT Amsterdam, The Netherlands

e-mail: eja@vumc.nl
The number of citations in 2008 of EJA articles from 2006 to 2007 was 32 and the total number of articles published in the $E J A$ in 2008 was also 32 . About half of the citations in 2008 was in the EJA itself. There is, however, evidence that $E J A$ articles are increasingly spreading through the wider scientific literature since 2004 , as a tripling of citations was observed in 2008 as compared to 2007. Best cited $E J A$ article so far has been the Iwarsson et al. (2004) article with 15 citations, followed by Attias-Donfut et al. (2005), Börsch-Supan et al. (2005), and Tomassini et al. (2004), with 12 citations each. Overall, $76 \%$ of citations of all of those best-cited articles appeared in established scientific journals other than the EJA. These numbers carry the good news that the assumption we started from in early 2004, of a critical mass of aging research in Europe within the journal's major themes, has been clearly confirmed by now. This critical mass is not only stable, but increasing. This is very good news for ageing research in Europe as well. We are proud and thankful that our journal is able to play a role here.

An important development has taken place in 2008 for all users of the EJA. The journal has gone online, see the website http://www.springer.com/social+sciences/aging/ journal/10433.

In this issue, we continue the EJA's section on "Critical Positions in Ageing Research". We regard this section as an opportunity to communicate innovative and provocative perspectives. This time, we use this forum to publish two recently launched declarations, which we regard as transporting key messages for two disciplines in the centre of the $E J A$, health and psychology, as well as to gerontology at large. First, the European Silver Paper on the Future of Health Promotion and Preventive Action, Basic Research and Clinical Aspects of Age-related Disease has been produced as result of the European Summit on Age-related 
Diseases, which was held in September 2008 in Wroclaw, Poland. Second, the Berlin Declaration on the Quality of Life for Older Adults: Closing the Gap between Scientific Knowledge and Intervention has been produced during the New Horizons Expert Workshop on Quality of life in Old Age, held as part of the XXIXth International Congress of Psychology in Berlin, in July 2008. In addition, the four original investigations in this volume centre on care provision and care receipt, and on long-term determinants of health. De Koker and Jacobs underscore in their research based on a Belgium population survey that socio-demographic variables do not play a uniform role in the prediction of informal caregiving, when it comes to co-resident versus extra-resident care. The article cautions against direct extrapolations of care supply from sociodemographic characteristics. Hansen, Christensen and Heinesen's somewhat provocative findings emerging from a Danish longitudinal data set support the notion that the provision of home care has neither a long-term effect on older women' ADL capacity nor on well-being, whereas there appears a negative association for men's functional ability, especially when initial ADL capacity is low. At the same time, in men with reduced ADL function home care shows the expected positive relationship with well-being. Perrig-Chiello, Jaeggi, Buschkuehl, Stähelin and Perrig's data stemming from the Basel Longitudinal Study on Ageing reveal substantial relations between personality traits in mid life (self-preoccupation) and psychological and physical well-being 24 years later. Finally, Rostad, Deeg and Schei show with a Norwegian population-based health survey among older women that substantial linkages between socio-structural variables and a range of health outcomes are maintained until very old age, even after controlling for a number of confounders.

What's ahead? This year will bring at least one special section, addressing the important issue of quality of life in old age, guest-edited by Ariela Lowenstein and Alan Walker. This is envisaged for issue 2009-2. Later this year, in July 2009, the conference of the International Association of Gerontology and Geriatrics will be held in Paris. During this conference, the EJA will have a reception in honour of our authors and reviewers, sponsored by Springer. We are looking forward to see you all in Paris in July 2009 in order to celebrate EJA's sixth volume.

\section{References}

Attias-Donfut C, Ogg J, Wolff F-C (2005) European patterns of intergenerational financial and time transfers. Eur $\mathrm{J}$ Ageing 2(3):161-173

Börsch-Supan A, Hank K, Jürges H (2005) A new comprehensive and international view on ageing: introducing the 'Survey of Health Ageing and Retirement in Europe'. Eur J Ageing 2(4):235-244

Iwarsson S, Wahl H-W, Nygren C (2004) Challenges of crossnational housing research with older people: lessons from the ENABLE-AGE project. Eur J Ageing 1(1):79-88

Tomassini C, Kalogirou S, Grundy E, Fokkema T, Martikainen P, Broese van Groenou M et al (2004) Contacts between elderly parents and their children in four European countries: current patterns and future prospects. Eur J Ageing 1(1):54-63 